\title{
Produção de mel por abelhas africanizadas em plantio de mamoneira
}

\author{
Honey production by Africanized honey bees in castor bean cropping \\ Marcelo de Oliveira Milfont ${ }^{\mathrm{I} *}$ Breno Magalhães Freitas $^{\mathrm{II}}$ \\ Rômulo Augusto Guedes Rizzardo ${ }^{\text {I }}$ Michelle de Oliveira Guimarães ${ }^{\mathrm{III}}$
}

\section{RESUMO}

O presente trabalho teve como objetivo investigar se abelhas Apis mellifera L. produzem mel ou não em plantio comercial de mamoneira (Ricinus communis L.). A pesquisa foi realizada no Núcleo de Produção Comunitária Santa Clara, Canto do Buriti, Piauí (PI). Dois apiários, com seis colônias cada, foram instalados em duas áreas de cultivo de mamona. A primeira área era mantida livre de ervas daninhas (área limpa), enquanto a outra não, apresentando estrato herbáceo entre as fileiras de cultivo (área suja). As colônias receberam melgueiras vazias à medida que necessário e eram pesadas a cada sete dias, até o final do experimento, aos 49 dias. Houve produção de mel em todas as colônias, porém a produção não diferiu $(P>0,05)$ entre os apiários a cada pesagem. A área limpa produziu uma média de $18,8 \pm 4,0 \mathrm{~kg}$ de mel/colônia, enquanto que, na área suja, a produtividade foi de 23,5 $\pm 3,0$. Conclui-se que abelhas Apis mellifera L. produzem $e$ armazenam mel quando introduzidas em áreas de cultivo comercial de mamona.

Palavras-chave: abelha melífera, mamona, mel de mamoneira, potencial apícola.

\section{ABSTRACT}

This research aimed to investigate whether Apis mellifera $\mathbf{L}$. bees produce honey in commercial plantations of castor bean (Ricinus communis L.) or not. This research was carried out in the Núcleo de Produção Comunitária Santa Clara, Canto do Buriti, Piauí, Brazil. Two apiaries of six colonies each were installed in two castor bean plots. The first plot was kept free of weeds (clean plot) while the other not (dirty area), presenting herbaceous vegetation between the castor bean rows.
Empty supers were given to the colonies as they were required and weighted every seven days afterwards until the end of the experiment 49 days later. There was honey production in all colonies, but honey production did not differ $(P>0.05)$ between apiaries at any weighing. The clean plot produced an average of $18.8 \pm 4.0 \mathrm{~kg}$ honey/colony while the dirty area reached 23.5 \pm 3.0 . It was concluded that Apis mellifera $L$. produce and store honey in castor bean cropping areas.

Key words: honey bee, castor bean, castor bean honey, beekeeping potential.

\section{INTRODUÇÃO}

A apicultura é uma atividade agropecuária que vem despertando grande interesse na região Nordeste, nos últimos anos, e seu crescimento tem se baseado no aproveitamento de floradas silvestres nativas (PEREIRA et al.,1989). No entanto, com os recentes incentivos do Governo Federal para produção de biodiesel, muitas áreas vêm sendo utilizadas para o cultivo de oleaginosas (OLIVEIRA E RAMALHO, 2006). Uma das culturas que vem substituindo a vegetação nativa é a da mamona (Ricinus communis L.). Pelo fato de ser adaptável às condições ambientais do Nordeste, a mamona vem sendo apontada como uma opção viável para geração de emprego e renda na região (LOPES et al., 2005).

'Programa de Doutorado Integrado em Zootecnia, Universidade Federal do Ceará (UFC), CP 12168, Campus do Pici, 60021-970, Fortaleza, CE, Brasil. E-mail: marcelo_m_agro@yahoo.com.br.*Autor para correspondência.

IIDepartamento de Zootecnia, Centro de Ciências Agrárias (CCA), UFC, Fortaleza, CE, Brasil.

IIIPrograma de Pós-graduação em Zootecnia, CCA, UFC, Fortaleza, CE, Brasil 
Tendo em vista que essa cultura ocupará milhares de hectares no semiárido nordestino para a produção de sementes (ROUSSEFF, 2004; MDA, 2006), a coleta de pólen e/ou mel agregaria valor à cultura, aumentando assim a rentabilidade da área (MILFONT, 2007). Porém, a mamona ainda é uma incógnita para a apicultura. Suas flores produzem apenas pólen, e há nectários extraflorais distribuídos por todos os pecíolos e todas as folhas da mamoneira, perfazendo de três a sete nectários por folha (BAKER et al., 1977), mas não existem, nas literaturas nacional e internacional, relatos acurados sobre a produção de néctar e pólen para a exploração apícola. As sementes possuem uma substância tóxica para animais homeotérmicos, chamada ricina (MOSHKIN, 1986), que, caso esteja presente no pólen e/ou néctar e seja tóxica a insetos, poderá causar prejuízos para a apicultura e desequilíbrios ecológicos.

Considerando a escassez de informações na literatura e a possibilidade de agregar valor em plantio de mamoneira por meio da apicultura, o presente trabalho foi realizado com o objetivo de avaliar a possibilidade de produção de mel por colônias de abelhas Apis mellifera L. em plantio de mamoneira.

\section{MATERIAL E MÉTODOS}

A pesquisa foi realizada em um plantio comercial de 3.115ha contínuos de mamona, no Núcleo de Produção Comunitária Santa Clara, pertencente à empresa Brasil Ecodiesel, e localizado no município de Canto do Buriti, Piauí, situado na região semiárida piauiense (IBGE, 2005). Segundo a classificação climática de KOEPPEN, o clima do município de Canto do Buriti é do tipo semiárido úmido, com estação chuvosa no verão, pluviosidade média de $813,80 \mathrm{~mm}$ anuais e temperatura média de $30,2^{\circ} \mathrm{C}$.

A execução do experimento ocorreu durante os meses de maio a julho de 2006, quando foram registradas uma temperatura média de $26,0 \pm 2,3^{\circ} \mathrm{C}$ e a umidade relativa do ar de $65,8 \pm 11,8 \%$, medidas com um termo-higrômetro digital MTH-1360, marca Ininipa.

Quando as mamoneiras já se encontravam com aproximadamente $50 \%$ de seus frutos vingados, foram instalados, durante a noite, dois apiários no centro da área de 3.115ha, distantes 1,5km entre eles, de forma a restringir o pastejo das abelhas à área cultivada com mamona. Os locais dos dois apiários eram semelhantes. No entanto, a área do primeiro apiário era mantida de forma mais livre possível de outras espécies vegetais (área limpa), e a área do segundo apiário não era capinada, apresentando outras espécies vegetais (área suja). Isso se fez necessário, pois, devido à grande extensão do plantio cobrindo área bem superior ao raio de ação das abelhas, estas não poderiam forragear em outras plantas, além das mamoneiras. A falta de capina em um dos apiários permitiria avaliar a atratividade relativa da mamoneira em relação às plantas silvestres da região, por meio do estudo da origem floral do mel, que porventura viesse a ser produzido. Se a mamoneira não for competitiva em relação a outras espécies, no apiário limpo, as abelhas produziriam mel monofloral de mamona, mas, no apiário sujo, a predominância seria das demais espécies vegetais presentes. No entanto, sendo a mamoneira competitiva em relação às demais plantas da área, seu mel deveria predominar em ambos os apiários. Para verificar isso, os méis produzidos nos dois apiários foram submetidos à análise melissopalinológica, segundo BARTH (1989).

Cada apiário constou de seis colméias, modelo Langstroth, habitadas por colônias bastante populosas de abelhas africanizadas (Apis mellifera L.), de origem e grau de mestiçagem desconhecidos, mas muito bem adaptadas a região e com bom estado sanitário. Na primeira semana, uma das colônias do apiário limpo foi excluída devido à perda de sua rainha. Cada ninho recebeu uma numeração (1 a 6) e a letra do seu respectivo apiário ( $\mathrm{L}$ - apiário da área limpa, S apiário da área suja), e as melgueiras numeradas foram adicionadas de acordo com a necessidade de cada colônia.

A coleta de dados foi realizada a cada sete dias a partir da instalação dos apiários, quando foram realizadas pesagens das melgueiras em balança Brião, modelo C 300, com carga máxima de 300kg e mínima de $4 \mathrm{~kg}$, com precisão de $100 \mathrm{~g}$, e os pesos foram anotados em uma ficha de controle de cada revisão. Ao final do experimento, 49 dias depois, foi coletado o mel das colméias que apresentaram produção. As melgueiras foram colhidas quando $80 \%$ da área dos seus favos se encontravam operculados, significando que o mel estava maduro, conforme SOUZA (2004). Cada melgueira colhida foi pesada para serem obtidas a produção individual de cada colônia e a produção total por apiário. A origem florística do mel foi comprovada por meio de análises melissopalinológicas em amostras de todas as datas de coleta, conforme BARTH (1989).

Os dados obtidos foram analisados comparando-se os apiários entre si a cada data de coleta, por meio de Análise de Variância. O delineamento utilizado foi o inteiramente casualizado.

\section{RESULTADOS E DISCUSSÃO}

Já no dia seguinte à introdução das colônias, as abelhas visitavam as flores da mamoneira em busca de pólen e nectários extraflorais, coletando néctar. Como 
conseqüência, houve um rápido acúmulo de mel nas melgueiras, na primeira quinzena do experimento, o que pode ser explicado pelo fato de que as colônias eram populosas, e o plantio de mamona estava em plena produção de néctar. Além disso, a ausência de mel nas melgueiras estimula a coleta de néctar por parte das operárias (FREE, 1987; WINSTON, 1987). As análises melissopalinológicas foram realizadas por especialista, tendo sido observados os parâmetros de biologia floral, como dioicismo e monoicismo, padrões de secreção de néctar e liberação de pólen, presença de nectários extraflorais, período de florescimento das espécies na área, além da quantidade total de pólen nas amostras e fatores de sub e super-representação de espécies botânicas no mel. Os resultados mostraram que as amostras de méis coletadas dos apiários (área limpa e área suja) possuíam uma quantidade insignificante de pólen. No entanto, em ambos os apiários, mais de $80 \%$ do pólen encontrado em todas as amostras eram de mamoneira (Tabela 1). Méis pobres em pólen são obtidos quando a espécie fonte do néctar é considerada sub-representada ou quando são produzidos a partir de fontes não-florais, como nectários extraflorais, onde a presença de pólen no néctar é improvável (BARTH, 1989). A mamoneira não possui nectários florais, no entanto ela é rica em nectários extraflorais dispersos por todas as partes vegetativas das plantas (BAKER et al., 1977) e que são avidamente visitados pelas abelhas Apis mellifera L.. Além disso, o pólen da mamoneira é anemófilo (seco e leve), facilmente dispersado pelo vento, o que favorece sua deposição, mesmo em pequenas quantidades, nos nectários extraflorais, levando ao seu aparecimento no mel. Portanto, devido à baixa incidência de pólen presente no mel e à participação praticamente nula das outras espécies em uma área de monocultivo de mamona, conclui-se que o mel colhido na área era proveniente de néctar da mamoneira. Méis monoflorais não são comuns no Brasil devido à sua produção ser predominante em áreas de vegetação nativa onde a diversidade florística é grande. No presente caso, em área de monocultivo com centenas de hectares contínuos de mamoneira e praticamente nenhuma diversidade florística, a mamoneira constituiu a única fonte considerável de néctar para as colônias.

Na figura 1, é possível observar que o acúmulo de mel nas melgueiras foi crescente por quase todo o período experimental, se estabilizando por volta dos 28 dias, no apiário de área limpa. No apiário da área considerada suja, o acúmulo de mel continuou crescendo até os 35 dias, estabilizando-se após esse período. Como as revisões semanais não permitiram restrição de espaço para depósito de mel e as colônias permaneciam fortes, a estabilização da curva de crescimento demonstra que as abelhas não acumularam mais mel nas melgueiras, após os 28 dias, na área limpa, e, na área suja, após 35 dias, sugerindo uma redução do fluxo de néctar que agora seria suficiente para manter as colônias sem que estas fizessem uso das reservas das melgueiras, mas insuficiente para permitir acúmulo de mais mel. Isso se deve, provavelmente, ao início do período seco, associado ao fim do ciclo de florescimento da mamona e das plantas silvestres. Apesar de a mamoneira ter nectários extraflorais (BAKER et al., 1977), estes possivelmente reduzem sensivelmente a secreção de néctar à medida que mais frutos vingam, já que eles funcionam como drenos das reservas e dos nutrientes da planta (TAIZ \& ZEIGER, 2004) A área suja, devido à maior diversidade florística, pode ter mantido o fluxo elevado de néctar por um período um pouco mais longo que a área limpa.

Tabela 1 - Número total e percentagem de grãos de pólen por espécie vegetal representada em amostras de méis coletadas em dois apiários de abelhas africanizadas (Apis mellifera L.) instalados em plantio comercial de mamoneira (Ricinus communis L.), no Município de Canto do Buriti, PI

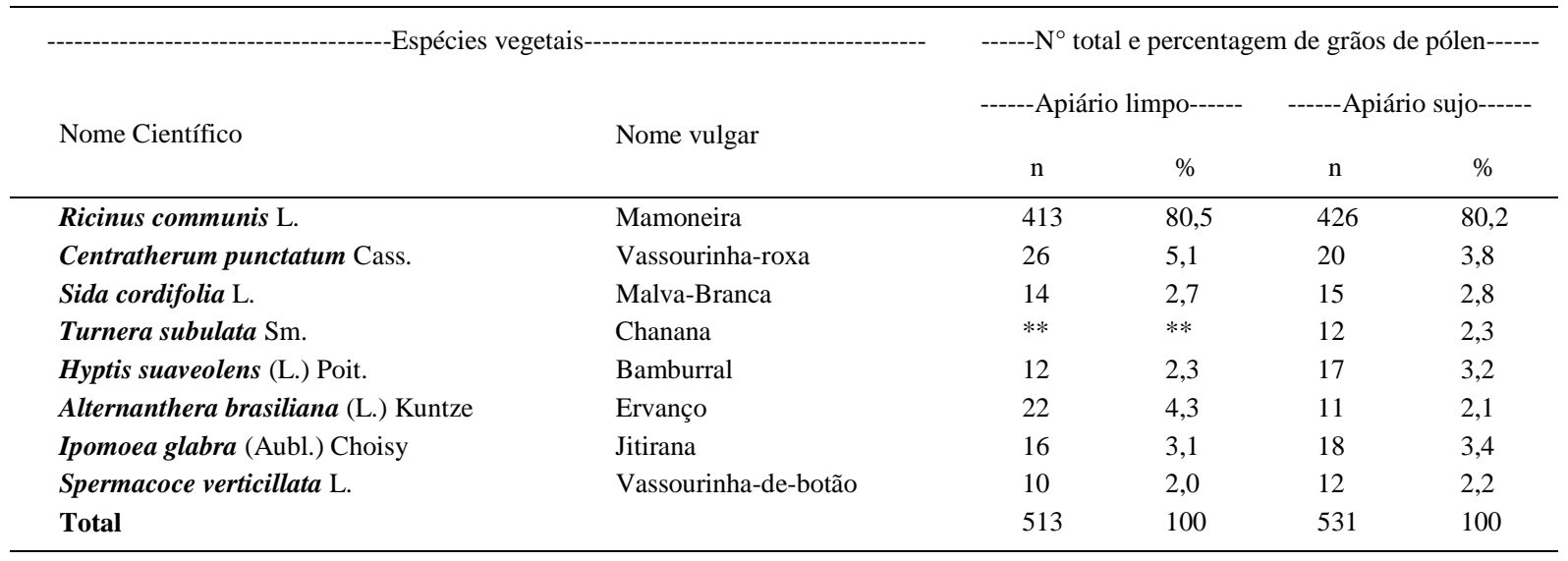

Ciência Rural, v.39, n.4, jul, 2009. 


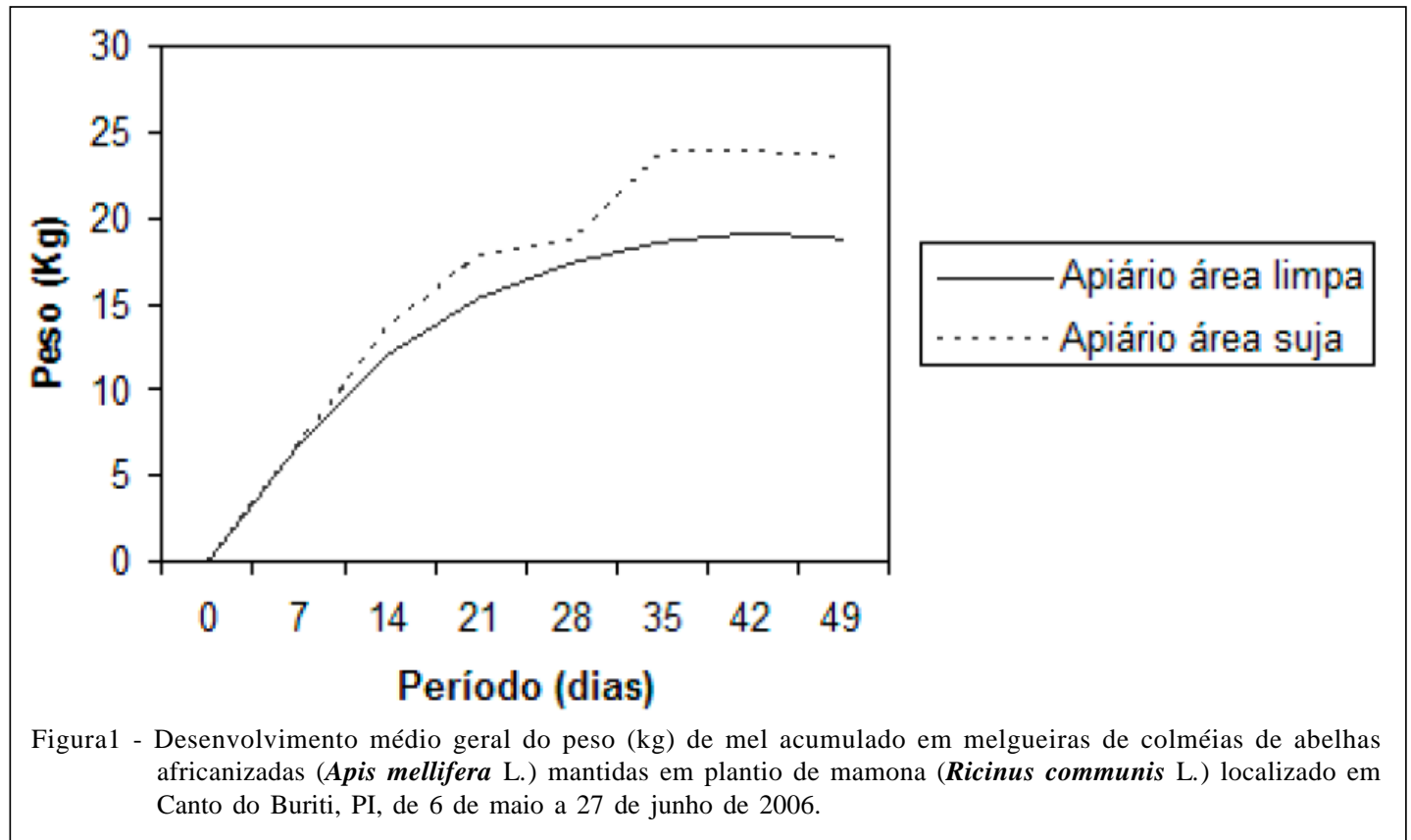

No final do experimento, aos 49 dias, a produção total foi de $235,2 \mathrm{~kg}$, sendo a produção do apiário da área suja superior em 33,31\%. Porém, esse apiário possuía uma colméia a mais do que o da área limpa devido à perda de uma colônia (Tabela 2). Não houve diferença significativa $(\mathrm{P}<0,05)$ entre as pesagens de mel armazenado nas melgueiras das colônias, nos apiários de área limpa e de área suja, a cada data de coleta. As médias com os respectivos erros-padrão da média do peso do mel acumulado, nos dois tratamentos, ao longo do experimento, estão na tabela 3.

O resultado demonstrou que, independentemente da presença ou não de outras espécies vegetais na área, foi possível produzir mel em plantio de mamoneira. A presença de outras espécies vegetais também não mostrou ser aspecto relevante estatisticamente na produção, diferentemente de outras espécies cultivadas que têm sua visitação por abelhas e/ou produção de mel afetadas pela competição por plantas silvestres (PERCIVAL, 1955; FREE, 1993; FREITAS, 1995). Porém, deve-se levar em conta que, mesmo sem capinas, a diversidade e a densidade de outras espécies, no apiário da área suja, eram baixa, podendo tal resultado mostrar-se diferente em situações de maior diversidade e/ou densidade de outras espécies vegetais.

A média obtida, no apiário de área limpa (18,82kg), em apenas 49 dias, assemelha-se à média de produtividade anual de mel no Brasil, inferior a $20 \mathrm{~kg}$ colméia $^{-1}$ ano $^{-1}$ (PEREZ et al.,2006). Já a produtividade média obtida, no apiário de área suja, foi superior à média brasileira, alcançando 23,51kg. Outro aspecto a se considerar é que as mamoneiras já se encontravam com aproximadamente $50 \%$ de seus frutos vingados, quando as colônias foram introduzidas. Caso a introdução das colônias fosse realizada mais precocemente, talvez a produtividade fosse ainda maior. No entanto, deve-se também considerar que os apiários continham apenas cinco e seis colônias, havendo a necessidade de se investigar a produção total em apiários com 30 colméias, número recomendado para áreas de caatinga.

Considerando-se a produção individual das colônias, observa-se uma grande variação na quantidade de mel produzida por colônia dentro e entre tratamentos. A área limpa apresentou, tanto a colônia

Tabela 2 - Produção de mel (kg) por colméia, produtividade média e produção total do apiário de área limpa e área suja em Canto do Buriti- PI, por um período de 49 dias.

\begin{tabular}{lll}
\hline Colméias & Apiário Área Limpa & Apiário Área Suja \\
\hline 1 & - & 17,8 \\
2 & 20,2 & 13,2 \\
3 & 9,4 & 28,6 \\
4 & 33,5 & 33,3 \\
5 & 15,6 & 26,4 \\
6 & 15,4 & 21,8 \\
Média \pm e.p.m & $18,8 \pm 4,0$ & $23,5 \pm 3,0$ \\
Total & 94,1 & 141,1 \\
\hline
\end{tabular}

Ciência Rural, v.39, n.4, jul, 2009. 
Tabela 3 - Evolução do peso (kg) médio de mel acumulado nas melgueiras de colônias de abelhas africanizadas, Apis mellifera L. mantidas em plantio de mamona por 49 dias em Canto do Buriti, PI.

\begin{tabular}{|c|c|c|c|c|}
\hline \multirow[b]{2}{*}{ Dias } & \multicolumn{2}{|c|}{ Apiário área limpa } & \multicolumn{2}{|c|}{ Apiário área suja } \\
\hline & $\mathrm{n}$ & x \pm e.p.m & $\mathrm{n}$ & x土e.p.m \\
\hline 0 & 5 & $0 \pm 0$ & 6 & $0 \pm 0$ \\
\hline 7 & 5 & $6,7 \pm 1,9$ & 6 & $6,8 \pm 1,0$ \\
\hline 14 & 5 & $12,1 \pm 1,9$ & 6 & $13,7 \pm 1,1$ \\
\hline 21 & 5 & $15,4 \pm 2,7$ & 6 & $17,7 \pm 1,6$ \\
\hline 28 & 5 & $17,5 \pm 3,9$ & 6 & $18,6 \pm 1,8$ \\
\hline 35 & 5 & $18,7 \pm 4,1$ & 6 & $23,9 \pm 3,2$ \\
\hline 42 & 5 & $19,1 \pm 4,1$ & 6 & $23,8 \pm 3,2$ \\
\hline 49 & 5 & $18,8 \pm 4,0$ & 6 & $23,5 \pm 3,0$ \\
\hline
\end{tabular}

que produziu mais mel (33,5kg), quanto a que produziu menos mel $(9,4 \mathrm{~kg})$ em todo o experimento, apresentando uma diferença de $24,1 \mathrm{~kg}$ entre elas. Na área suja, a situação foi semelhante, com a colônia mais produtiva tendo acumulado 33,3kg de mel, enquanto que a menos produtiva armazenou $13,2 \mathrm{~kg}$, perfazendo uma diferença entre elas de $20,1 \mathrm{~kg}$ de mel e deixando claro que a vegetação das áreas não influenciou na produção de mel. Segundo ALMEIDA e CENTENO (1994), a produção de mel é influenciada pelo meio ambiente (4,7\%), pelas condições internas das colônias $(18,1 \%)$ e pelos fatores genéticos (77,2\%). Como no presente estudo as condições ambientais eram idênticas para cada colônia do mesmo tratamento e o manejo aplicado uniformizou ao máximo as condições das colônias, pode-se concluir que a diferença em produtividade entre elas deveu-se basicamente à variabilidade genética das colônias (SOUZA, 1996). De fato, Duay (1996) demonstrou que apiários de Apis mellifera $\mathbf{L}$. formados por colônias capturadas na mata e de constituição genética desconhecida produzem significativamente menos mel do que aqueles compostos de colônias com rainhas selecionadas para alta produção de mel. Dessa forma, o uso de colônias com nível de produtividade média em torno de $30 \mathrm{~kg}$, como foi observado ser possível nas duas condições testadas aqui, aumentaria significativamente a produção de mel em cultivos de mamona.

\section{CONCLUSÃO}

As abelhas Apis mellifera L. conseguem produzir e armazenar mel quando introduzidas em áreas de cultivo comercial de mamona Ricinus communis $\mathbf{L}$.. Assim, o cultivo comercial de mamona apresenta potencial para a exploração apícola e deve ser investigado quanto à sua produção de mel por abelhas Apis mellifera em situação de apiários comerciais.

\section{AGRADECIMENTOS}

Os autores agradecem ao Fundo de Desenvolvimento Científico e Tecnológico (FUNDECI), pela contribuição financeira; à Fundação Cearense de Apoio ao Desenvolvimento Científico e Tecnológico (FUNCAP), pela bolsa de mestrado concedida a Marcelo de Oliveira Milfont; ao Conselho Nacional de Desenvolvimento Científico e Tecnológico (CNPq), pela bolsa de mestrado de Rômulo Augusto Guedes Rizzardo e de produtividade em pesquisa de Breno Magalhães Freitas (484587/2007-2); e à empresa Brasil Ecodiesel, pela concessão da área, logística e utilização de suas instalações.

\section{APRESENTAÇÃo} primeiro autor

Este trabalho é parte da dissertação de mestrado do

\section{REFERÊNCIAS}

ALMEIDA, M.J.O.F.; CENTENO, A.J. Produção das abelhas, Goiânia, GO. In: CONGRESSO BRASILEIRO DE APICULTURA, 10., 1994, Goiânia, GO. Anais... Goiânia: Confederação Brasileira de Apicultura, 1994. p.346.

BAKER, D.A. et al. Study of the Extrafloral Nectaries of Ricinus communis. New Phytologist, v.81, n.1, p. 129-137, 1977. Disponível em: <http://www3.interscience.wiley.com/journal/ 119615240/abstract?CRETRY $=1 \&$ SRETRY=0>. Doi: $10.1111 /$ j.1469-8137.1978.tb01612.x.

BARTH, O.M. O pólem no mel brasileiro. Rio de Janeiro : Gráfica Luxor, 1989. 150p.

DUAY, P. Manejo para aumento da produtividade. In: CONGRESSO BRASILEIRO DE APICULTURA, 11., 1996, Teresina, PI. Anais... Teresina: Confederação Brasileira de Apicultura, 1996. V.1, 434p. p.121-124.

FREE, J.B. Pheromones of social bees. London: Chapman and Hall, 1987. 218p.il.__. Insect pollination of crops. London: Academic, 1993. 684p.

FREITAS, B.M. Does Borreria verticilatta compete with cashew (Anacardium occidentale) for pollination by honey bee? In: INTERNATIONAL CONGRESS OF APIMONDIA, 34., Lausanne, Switzerland. Proceedings... Lausanne: Apimondia Publishing House, 1995. p.260-264.

IBGE. Instituto Brasileiro de Geografia e Estatística. Capturado em $10 \mathrm{dez} 2005$. Online. Disponível na internet. http://www.sidraibge.gov.br.

LOPES, J. S. da. et al. Produção de mamona e biodiesel: uma oportunidade para o semiárido. Bahia Agrícola, v.7, n.1, p.37-49, 2005.

MDA. Selo combustível Social. Programa Nacional de Produção e Uso de Biodiesel. Ministério do Desenvolvimento Agrário, 2006. Acesso em 12 de fev. 2007. On line. Disponível em: <http://www.mda.gov.br/saf/arquivos/ 0705112061.doc>

Ciência Rural, v.39, n.4, jul, 2009. 
MILFONT, M.O. O potencial da mamoneira (Ricinus communis L.) para a exploração apícola: produção, toxidez e qualidade de mel. 2007. 90f. Dissertação (Mestrado em Zootecnia) - Universidade Federal do Ceará.

MOSHKIN, V.A; PERESTOVA, T.A. Morphology and anatomy. In: MOSHKIN, V.A (Ed). Castor. New Delhi: Amerind Publishing, 1986. p.28-33.

OLIVEIRA, A.J. de; RAMALHO, J. Plano Nacional de Agroenergia 2006-2011 / Ministério da Agricultura, Pecuária e Abastecimento, Secretaria de Produção e Agroenergia. 2.ed. rev. Brasília, DF: Embrapa Informação Tecnológica, 2006. 110p.

PERCIVAL, M.S. The presentation of pollen in certain angiosperms and its collection by Apis mellifera. New Phytologist, n.54, p.353-368, 1955.

PEREIRA, R.M de A. et al. Estudos fenológicos de algumas espécies lenhosas e herbáceas da caatinga. Ciência Agronômica, v.20, n.1/2, p.11-20, 1989.
PEREZ, L.H. et al. Câmbio e embargo europeu podem prejudicar exportações apícolas em 2006. Mensagem Doce, n.86, p.2226, 2006.

ROUSSEFF, D. Biodiesel, O novo combustível do Brasil. Programa Nacional de Produção e uso do Biodiesel. Ministério de Minas e Energia. 2004. Acesso em: 15 jan. 2007. On line. Disponível em: http://biodiesel.gov.br/docs/Apres_MinisteME_0612-04.pdf>.

SOUZA, D.C. Seleção de rainhas (Apis mellifera L.). In: CONGRESSO BRASILEIRO DE APICULTURA, 11., 1996, Teresina, PI. Anais... Teresina: Confederação Brasileira de Apicultura, 1996. V.1. 434p. p.125-130.

SOUZA, D.C. Importância socioeconômica. In: Apicultura: manual do agente de desenvolvimento rural. Brasília: Sebrae, 2004. Cap.4, p.35-41.

TAIZ, L.; ZEIGER, E. Fisiologia vegetal. Porto Alegre: Artmed, 2004. 719p.

WINSTON, M.L. The biology of the honey bee. London, England : Harvard University, 1987. 281p. 